\section{Evaluation of new primers for detecting toxigenic vibrio cholerae by multiplex PCR}

\author{
Jalil F. Mehrabadi, ${ }^{1}$ Parisa Morsali, ${ }^{2}$ \\ Hamideh Rohani nejad, 3 \\ Abbas Ali Imani Fooladi, ${ }^{4}$ Sarah Najafy \\ 1 MARS Bioinformatics Institute, Tehran; \\ 2AJA University of Medical Sciences, \\ Tehran; ${ }^{3}$ Department of Microbiology, \\ Faculty of Basic Sciences, Qom branch, \\ Islamic Azad University, Qom; ${ }^{4}$ Applied \\ Microbiology Research Center, \\ Baqiyatallah University of Medical \\ Sciences, Tehran; ${ }^{5}$ Department of \\ Microbiology, Faculty of Basic and \\ Medical Sciences, Zanjan branch, Islamic \\ Azad University, Zanja, Iran
}

\begin{abstract}
Vibrio cholerae is the etiological agent of cholera that has emerged as an endemic disease in different regions of the world in recent years. Traditional microbial culture and microscopy methods are considered to be the best standard for diagnosing $V$. cholerae infection. These methods, however, delay any available confirmatory answer by days. Molecular methods have the potential to provide sensitive, accurate, and rapid analysis of $V$. cholerae infection. We have developed a multiplex PCR assay to detect virulence and toxigenic-associated (VTA) genes (ctxA, tcpA, and ompW). To evaluate PCR specificity, additional bacteria from the enterobacteriaceae family (Salmonella typhi, Shigella dysantry, and entrotoxigenic E. coli) and Aeromonas hidrophyla were examined in this study. Specificity tests were evaluated using the genome dilution method. Importantly, the results show that our PCR specificity method represents the best tool for the rapid detection of VTA genes because of its simplicity, cost effectiveness, and accuracy. This multiplex PCR method can be used for examining the existence of VTA genes in patient samples, and therefore will distinguish $V$. cholerae from other vibrios and bacteria. This method is able to detect 10-100 colony forming units (CFUs) of V.Cholerae and 8.5-85 picograms (pg) of genomic DNA. The multiplex PCR method is also more specific and sensitive than other methods, validating it as an appropriate and sensitive tool for detecting the presence of toxigenic and pathogenic $V$. cholerae.
\end{abstract}

\section{Introduction}

Diarrheal diseases are among the greatest world healthcare problems. Cholera is one of the most serious diarrheal diseases, causing an epidemic with Vibrio cholerae 01 or 0139 serogroups. ${ }^{1}$ Primary virulence factors of V.cholerae are cholera toxin and toxin-co-regulated pilus, which are encoded by the ctxAB and tcpA genes, respectively. ${ }^{2,3}$ CtxA and tcpA are uncommon in environmental strains, ${ }^{4}$ yet are responsible for the pathogenesis in V.cholerae serogroups 01 and 0139.5-7 Biochemical methods for the detection of V.cholerae are timeconsuming and can require 2 to 7 days for assessment. Cholera detection requires urgent testing, and efficiency is a critical factor for determining the usefulness of any detection method. Moreover, special expertise is required to process these tests, but such expertise is not available in all laboratories. ${ }^{8}$ Thus, rapid detection tests are functional and necessary for creating a better detection method for cholera infection. These tests are fast and sensitive techniques for the primary diagnosis and control of pathogenicity, and employ several biotype-specific genes to diagnose the presence of V.cholerae, such as $c t x \mathrm{~A}$ and $t c p \mathrm{~A}$. The aim of this study was to develop such an assay for the rapid detection of pathogenic and toxogenic $V$. cholerae bacteria. To develop a standard, accurate, and rapid method for the detection of $V$. cholerae, we designed the Multiplex PCR method for genes $c t x \mathrm{~A}, t c p \mathrm{~A}$, and $o m p \mathrm{~W}$.

\section{Materials and Methods}

\section{Bacterial strains}

$V$. cholerae 01 and non- $0_{1}$ stains, Salmonella typhi, Shigella dysenteriae, Aeromonas hydrophila, and Enterotoxigenic Escherichia coli (ETEC) were all included in this study and were provided by the Bu-Ali reference laboratory in Iran.

\section{DNA extraction}

All strains were cultured in pepton soy broth
Correspondence: Jalil F. Mehrabadi, MARS Bioinformatics Institute, Tehran, Iran.

E-mail: jalil.fallah@gmail.com

Key words: Vibrio cholerae, multiplex PCR, VAT genes, vibrio, toxigenic.

Received for publication: 3 March 2011.

Revision received: 9 April 2011.

Accepted for publication: 10 May 2011.

This work is licensed under a Creative Commons Attribution 3.0 License (by-nc 3.0).

(C) Copyright J.F. Mehrabadi et al., 2011

Licensee PAGEPress, Italy

Microbiology Research 2011; 3:e1

doi:10.4081/mr.2011.e1

and incubated at $37^{\circ} \mathrm{C}$ overnight. Genomic DNA was extracted using the DNA Pure Extraction Kit (Bioneer, South Korea) according to the manufacturer's protocol.

\section{Target sequences and primers}

Three target sequences were used that encoded cholera toxin (ctx $\mathrm{AB})$, toxin coregulated pilus (tcpA), and outer membrane protein (ompW). The primers used were $c t x A, t c p A$, ompW (NC-012583, NC-009457, NC-012583), respectively, and are shown in Table 1.

\section{PCR amplification for uniplex and multiplex assays}

Three uniplex PCR assays were carried out in $50 \mu \mathrm{L}$ reaction volumes consisting of $20 \mathrm{mM}$ Tris-HCl (pH 8.4), 1 unit of Platinum Taq DNA Polymerase (Invitrogen, Carlsbad, California, USA), $0.2 \mathrm{mM}$ each of dATP, dCTP, dGTP, and dTTP (Invitrogen, Carlsbad, California, USA), $2 \mathrm{mM} \mathrm{MgCl} 2,25$ pmol of each primer, and $50 \mathrm{ng}$ of DNA template. Multiplex PCR reactions were performed with the simultaneous addition of primers for the three genes in the same mixture. Thermocycling conditions consisted of an initial denaturation at $94^{\circ} \mathrm{C}$ for $4 \mathrm{~min}$, followed by 35 cycles of 1 min of denaturation at $94^{\circ} \mathrm{C}, 1 \mathrm{~min}$ of annealing at $50^{\circ} \mathrm{C}$, and $1 \mathrm{~min}$ of extension at $72^{\circ} \mathrm{C}$. The final extension was carried out at $72^{\circ} \mathrm{C}$ for $5 \mathrm{~min}$.

Table 1. Primer sequences used in this survey.

\begin{tabular}{lccc} 
Primers & \multicolumn{1}{c}{ Sequence } & Target gene & Amplicon sive \\
ctxF & ggTCTTATgCCAgAggACAg & ctxA & $219 \mathrm{bp}$ \\
ctxR & gTTgggTgCAgTggCTATAAC & ctxA & \\
\hline tcpF & ATTCTTggTgATCTCATgATAAgg & tcpA & $295 \mathrm{bp}$ \\
tcpR & TTAATTCACCACAAATATCTgcc & tcpA & \\
\hline ompF & CACCAAgAAggTgACTTTATTgTg & ompW & $588 \mathrm{bp}$ \\
ompR & gAACTTATAACCACCCgCg & ompW & \\
\hline
\end{tabular}




\section{Specificity test}

For assessment and specificity determination of the designed primers, genomic DNA of $V$. cholerae 01 and non-01, ETEC, S. typhi, Sh.dysenteriae, and A. hydrophila was used as templates in uni- and multiplex PCR reactions.

\section{Sensitivity test}

For detection of $V$. cholerae genomic DNA, serial dilutions of DNA were made ranging from $100 \mathrm{ng}$ to $10 \mathrm{pg}$. PCR was performed at each dilution value.

\section{Results}

\section{PCR of ctxA, tcpA, and ompW genes}

$C t x \mathrm{~A}, t c p \mathrm{~A}$, and $o m p \mathrm{~W}$ genes were amplified by PCR using genomic DNA of both $V$. cholerae 01 and non-01 serogroups. The amplicons related to $V$. cholerae $01 c t x \mathrm{~A}, t c p \mathrm{~A}$ and $o m p \mathrm{~W}$ genes were $219 \mathrm{bp}, 295 \mathrm{bp}$, and $558 \mathrm{bp}$, respectively. The PCR reaction with the $V$. cholerae non-01 ompW gene was the only reaction that resulted in an amplicon of the same size (Figure 1).

\section{Specificity test for ctxA, tcpA, and ompW genes}

To confirm the specificity of the designed primers, genomic DNA of $S$. typhi, Sh. dysenteriae, A. hydrophila, and ETEC was used as a template. The results showed that the designed primers were specific for these genes, since no additional amplicons were detected on gel electrophoresis.

\section{Sensitivity test for $c t x A, \operatorname{tcp} A$, and ompW genes}

Although the infective dose of $V$. cholerae is approximately $10^{8}$ bacteria, performing a sensitivity test by PCR is imperative for determining the robustness of the test. Genomic DNA of V. cholerae 01 was extracted and diluted from 100 ng to $10 \mathrm{pg}$, and PCR was performed at each concentration. The minimum concentration of genomic DNA at which ctxA, tcpA, and ompW could be detected were $8.5,85$, and $85 \mathrm{pg}$, respectively. Moreover, the ompW gene was detected when the DNA was diluted to $14 \mathrm{pg}$ in the in the V. cholerae non-01 sample (Figure 2).

\section{Triplex PCR of $V$. cholerae $\mathrm{O} 1$ and non-O1 serogroups}

Using all three sets of primers and $V$. cholerae 01 genomic DNA in a single PCR assay, the $c t x \mathrm{~A}, t c p \mathrm{~A}$, and $o m p \mathrm{~W}$ genes were amplified. The amplicon sizes were $219 \mathrm{bp}, 295 \mathrm{bp}$, and
588 bp for the $c t x \mathrm{~A}, t c p \mathrm{~A}$, and ompW genes, respectively (Figure 1). The same triplex PCR reaction was carried out for detection of three genes in the $V$. cholerae non-01 strain, but only showed a 588 bp amplicon, which corresponded to ompW.

\section{Discussion}

The standard methods in microbiology that are traditionally used to detect $V$. cholerae infection have several disadvantages. Therefore, a rapid and more efficient method is needed. We employed an updated nucleic acid based approach based on PCR assays, which simplified bacteria detection. It has been shown that toxicon-regulated pili are used by $V$. cholerae for intestinal colonization, and the main mediator is the regulatory $c t x A$ gene. ${ }^{9}$ Therefore, an important standard gene for the detection of toxigenic $V$. cholerae is ctxA. ${ }^{10,11}$

Nandi et al. designed rapid detection methods using ompW and tox $\mathrm{R}$ and analyzed $254 \mathrm{~V}$. cholerae samples. ${ }^{12}$ Samples 229 and 239 were shown to have the ompW and tox $\mathrm{R}$ genes, respectively. This was reported for the 01 , 0139, non-01, and non-0139 serogroups, but was undetectable in other Vibrio serogroups. ${ }^{12}$ In that study, similar to our research, the ompW gene was $588 \mathrm{bp}$ in length. In our particular test, ctxA was used for $V$. cholerae detection.

Panikar et al. applied DNA microarrays and Multiplex PCR to detect pathogenic V. choler$a e .{ }^{13}$ In that particular study, 10 genes were used for diagnosing the Vibrio family. For $V$. volnificus, rrh and viuB were detected with specific primers and probes. Moreover, for $V$. parahaemolyticus, the $t h, t d h, t r h$, and ORF8 genes were used for bacterial detection; for $V$. cholerae, the ompU, tox $\mathrm{R}$, and $t c p \mathrm{I}$ genes were used for detection; and for El Tor and the classical biotype, the $h l y$ A gene was used for bacterial detection. The specificity for this method was $100 \%$. Diagnosis in non-broth culture was $100-1000 \mathrm{CFU} / \mathrm{mL}$, while it was $1 \mathrm{CFU} / \mathrm{mL}$ in broth culture. The genes ompW, ctxA, and tcpA were used to detect $V$. cholerae stains. ${ }^{13}$

Gubala et al. applied Multiplex Real Time PCR to amplify $r t x \mathrm{~A}, e p s \mathrm{M}, t c p \mathrm{~A}$, and $m s h \mathrm{~A}$ genes as a method for detecting toxigenic $V$. cholere. ${ }^{14}$ In this study, the tcpA gene was not detected in the non-01 and 01 serogroups. Non-Vibrio was not detected in the specificity analysis of primers, but the tcpA gene was detected in $V$. cholerae serogroups 01 and non01. ${ }^{14}$

Katsaki Hoshino and his group applied Multiplex PCR to detect toxigenic Vibrio 01 and 0139 using the $c t x \mathrm{~A}$ and $r f b$ genes. ${ }^{15}$ Of
121 patient waste samples, 38 samples tested positive by this method, and importantly, the method sensitivity was $100 \%$ and specificity was $95.5 \%$ compared to the bacteriologic culture method. Detection in this study was reported for $V$. cholerae 01 at 65 CFUs and for 0139 at $200 \mathrm{CFUs}{ }^{15}$

Dalsgaard et al. analyzed the virulence of $V$. cholerae non-01 and non-0139 by amplifying genes ctxA and tcpA via PCR. ${ }^{16}$ In this study, $c t x \mathrm{~A}$ and $t c p \mathrm{~A}$ genes were detected in the $V$. cholerae serogroup 01.

In our research study, the ompW gene was used to detect all Vibrio species. Multiplex PCR was applied for rapid and specific detection of Vibrio containing the toxigenic gene as well as other Vibrio of gram-negative bacteria. In addition to using the cholera toxin gene to specifically identify $V$. cholerae pathogenic strains, we applied the $t c p \mathrm{~A}$ and $o m p \mathrm{~W}$ genes for detection of other $V$. cholerae species. Method sensitivity was analyzed by diluting $V$. cholerae bac-

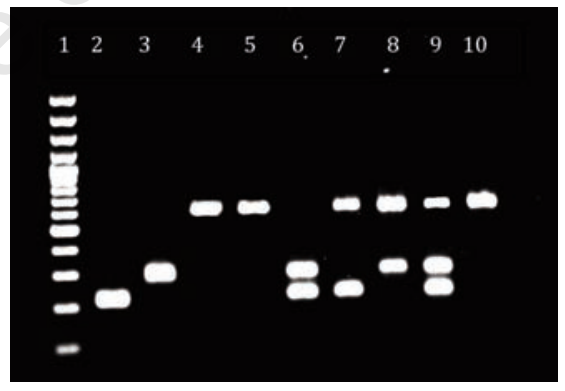

Figure 1. PCR (uni, duplex and triplex) of V. cholerae O1. Lane 1(Ladder 100bp), lane 2(ctxA amplicon, $219 \mathrm{bp}$ ), lane3 tcpA amplicon, 295 bp), lane4 (ompW amplicon of $\mathrm{O} 1$ serotype, $588 \mathrm{bp}$ ) lane $5(\mathrm{omp} \mathrm{W}$ amplicon of non-O1 serotype, $588 \mathrm{bp}$ ), lane 6(duplex PCR for $\operatorname{ctxA} \& \operatorname{tcpA}$ ), lane 7(duplex PCR for ompW \& tcpA), lane 8 (duplex PCR for ctxA \& ompW), lane9 (triplex PCR for $t c p A$, ompW \& ctxA of $V$. cholerae O1), lane 10(triplex PCR for tcpA, omp W \& ctxA of $V$. cholerae nonO1).

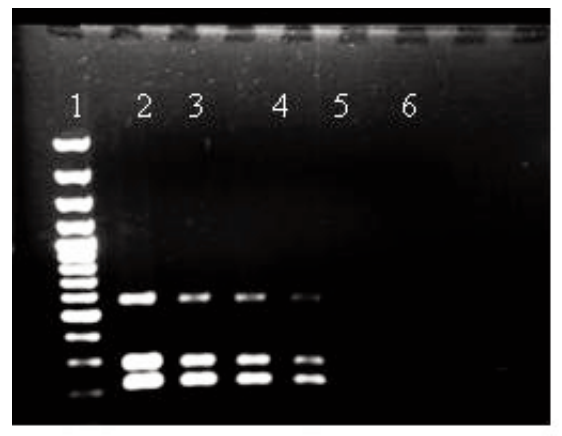

Figure 2. Sensitivity test of triplex PCR of V. cholerae $\mathrm{O} 1$. Lane1(ladder100bp), lane 2(1/10dilution), lane3 (1/100 dilution), lane $4(1 / 1000$ dilution $)$, lane $5(1 / 10000$ dilution), lane6(1/100000 dilution). 
terial genomic DNA, and specificity was determined by using bacteria genomes of S.typhi, A. hydrophila, Sh. dysantri, and ETEC. Multiplex PCR distinguished the ctxA gene at a template concentration of $85 \mathrm{pg}$, while uniplex PCR distinguished the gene at a template concentration of $8.0 \mathrm{pg}$.

The method described in this study was applied for the rapid detection of $V$. cholerae from water and food sources. Based on the results of our study and others, the multiplex PCR method is the best approach for the rapid detection of cholera infection and provides a useful method of detection even when the bacterial count is low.

\section{References}

1. Pang B, Yan M, Cui Z, et al. Genetic Diversity of Toxigenic and Nontoxigenic Vibrio cholerae Serogroups 01 and 0139 Revealed by Array-Based Comparative Genomic Hybridization. J Bactriol 2007; 189:4837-49.

2. Dalmasso A, Civera T, Bottero MT. Multiplex primer-extension assay for identification of six pathogenic vibrios. Int $\mathrm{J}$ Food Microbiol 2009;129:21-5.

3. Kaper JB, Morris JG Jr, Levine MM. Cholera. Clin Microbiol Rev 1995;8:48-86.

4. You Y, Fu C, Zeng X, et al.A novel DNA microarray for rapid diagnosis of enteropathogenic bacteria in stool specimens of patients with diarrhea. J Microbiol Methods 2008;75:566-71.

5. Kumar P, Peter WA, Thomas S. Rapid Detection of Virulence-Associated Genes in Environmental Strains of Vibrio cholerae by Multiplex PCR. Curr Microbiol 2010;60:199-202.

6. Sharma C, Thungapathra M, Ghosh A, et al. Molecular analysis of non-01,non-0139 Vibrio cholerae associated with an unusual upsurge in the incidence of cholera-like disease in Cacutta, India. J Clin Microbial 1998;36:756-63.

7. Kurazono H, Pal A, Bag PK, et al. distribution of genes encoding cholera toxin, zonula occludens toxin accessory cholera toxin and El Tor hemolysin in Vibrio cholerae of diverse origins. Microb Pathog 1995;18:231-5.

8. Tarr CL, Patel JS, Puhr ND, et al. Identification of Vibrio Isolates by a Multiplex PCR Assay and rpoB Sequence Determination. J Clin Microbiol 2007;45: 134-40.

9. Bina J, Zhu J, Dziejman M, et al. ToxR regulon of Vibrio cholerae and its expression in vibrios shed by cholera patients. PNAS 2003;100:2801-6.

10. Taylor RK, Miller VL, Flulong DB, Mekalanos JJ. Use of phoA gene fusions to identify a pilus colonization factor coordinately regulated with cholera toxin. Proc Natl Acad Sci USA 1987;84:2833-7.
11. Fields PI, Popovic T, Wachsmuth K, Olsvik Q. Use of polymerase chain reaction for detection of toxigenic Vibrio cholerae 01 strains from the Latin American cholera epidemic. J Clin Microbiol 1992;30:211821.

12. Nandi B, Nandy RK, Mukhopadhya S, et al. Rapid Method for Species-Specific Identification of Vibrio cholerae Using Primers Targeted to the Gene of Outer Membrane Protein OmpW. J Clin Microbiol 2000;38: 4145-51.

13. Panickar GDR, Krug CNJ, Bej AK. Detecton of pathogenic Vibrio spp.in selfish by using multiplex PCR and DNA microaarays. Appl Environ Microbial 2004; 70:7436-44.

14. Gubala AJ. Multiplex real-time PCR detection of Vibrio cholerae, J Microbiol Methods 2006;65:278-93.

15. Hoshino K, Yammasaki S, Mukhopadhyay AK, et al. Development and evaluation of multiplex PCR assay for rapid detection of toxigenic Vibrio cholerae 01 and 0139. FEMS Immunol Med Microbiol 1998;20: 201-7.

16. Dalsgaard AMJ, Albert D $\neg \mathrm{N}$, Taylor T, et al. Characterization of Vibrio cholerae non01 serogroups obtained froman outbreak of diarrhea in Lima. Peru J Clin Microbial 1995;33:2715-22. 